\title{
A qualitative assessment of long distance truck drivers' vulnerability to HIV/AIDS in Itajai, southern Brazil
}

\author{
M. MALTA $^{1}, z$, F. 1.. BASTOS ${ }^{I}$, E. M. PEREIRA-KOLLER\ M. D. CUNHA। \\ C. MARQUES $\backslash$ \& S. A, STRATHDEE ${ }^{Z}, 3$
}

IOswaldo Cruz Foundation, Rio de:'Janeiro, Brazil, 2.'JohnsHopk.ins Bloomberg School of Public Health, Baltimore USA, 3 University of California San Diego School of Mediaine, California, USA, and 4 vale do ltaJai Uniz)ersity, ltaJai, Brazil

\begin{abstract}
Itajai is the largest port in southern Brazil and has one of the nation's highest AIDS incidence rates. Since over 400 truck drivers enter the city daily, they may playa key role in the HIV/AIDS epidemic due to transactions with commercial sex workers (CSWs) and/or substance use. We conducted a rapid assessment to establish the context of HIV vulnerability among truckers and CSWs in Itajai. Forty three in-depth interviews and eight focus groups were conducted with truckers and CSWs. Two truck-driving routes involving brothels, meeting places and drug-use locations were mapped and field observations were collected. Tapes and field notes were transcribed and analyzed for emerging themes. Trual, drivers typically had unprotected sex with several partners, including CSWs and truckstop employees. Both truckers and CSWs had low perceived HIV risk in spite of being engaged in high-risk sex behaviors. Use of alcohol and amphetamine-like drugs was frequent among truckers and appeared to influence unsafe sex practices. Knowledge about amphetamine-related risks was low, as was access to health services and HIV/AIDS behavioral interventions. Interventions, targeting truckers, CSI'V'sand truckstop employees, are needed that traverse cities, states and borders and take into account: seasonality, spatial context and workplace conditions.
\end{abstract}

\section{Introduction}

Truck drivers play an important role in HIV/AIDS transmission in many countries (Gibney et aI., 2003; Sunmola, 2005). A study of truck drivers/assistants. in southern India found that prevalence of HIV, syphilis and hepatitis B were 15.9\%, $13.3 \%$ and $21.2 \%$, respectively. Longer truck driving careers and trips were significantly associated with HIV infection (Manjunath et aI., 2002). Studies conducted in Thailand, Bangladesh, Indonesia, Nigeria and Florida (USA) indicate that condom use among truck drivers is low and/or inconsistent (Gibney et aI., 2003; Morris et aI., 1996; Stratford et aI., 2000; Sugihantono et aI., 2003; Sunmola, 2005). A study of HIV-positive truckers in Bangladesh found that over one third did not change their sexual behavior after learning that they were HIV-positive (Gibney et aI., 2003).

Studies of truck drivers in Brazil are scarce. A study conducted with 300 male truck drivers in Santos found that the use of 'rebite' (a stimulant) was reported by $43 \%$ and was associated with syphilis (Lacerda et aI., 1997). A second Santos study found that $69 \%$ of truck drivers had a low self-perceived HIV risk in spite of their inconsistent condom use with multiple partners (Villarinho et aI., 2002).

We conducted a rapid assessment using qualitative methodologies to assess the context of risk behaviors occurring among truck drivers and CSWs at roadside truck stops in Itajai, the municipality with the largest port in southern Brazil and one of the highest AIDS incidence rates (Brazilian Ministry of Health, 2004). Itajai has a population of around 150,000 inhabitants and is a transit point for approximately 400-500 truck drivers per day. Since truck drivers are a highly mobile population and could serve as a transmission bridge to remote populations, these findings could have implications for future interventions.

\section{Methods}

A rapid assessment study was conducted in 2003 using in-depth interviews, focus groups, field observations and mapping based on methods described previously (Needle et aI., 2003; Stimson et aI., 2003) .

COlTespondence: Monica Malta, Johns Hopkins Bloomberg School of Public Health, Department of Mental Health, Room 759 , 624 North Broadway St, Baltimore, MD 21205, USA., Tel: +1 (410) 9551813. Fax: +1 (410) 6148132. E-mail: mmalta@ihsph.edu/momalta@ cict.fiocruz. br 
In-depth interviews were used to explore local meanings and understandings of health problems and health behaviors related to HIV/AIDS and drug abuse and perceived HIV risks. Truck drivers were mainly recruited in two main roadside truck stops; CSWs were recruited in the same two truck stops, two brothels, highways and bars. Of 30 truck drivers and 13 CSWs, all but one of the truck drivers were male and four CSWs were male.

Interviews were semi-structured, lasted 60-90 minutes and used a script that included probes about drug use and sexual risk behavior, HIV/STI knowledge and attitudes, access to voluntary counceling and testing (VCT), health services and HIV/ AIDS interventions and effectiveness of available health services. Contact sheets were used to summarize interviews or other field contacts and to select subsequent contacts (Miles \& Huberman, 1994). All interviews were conducted, tape-recorded and coded in Portuguese, translated into English and transcribed into an Atlas.ti database (Muhr, 1997).

Eight focus groups were conducted, six with truck drivers and two with CSWs, comprising six to eight persons and lasting 60 90 minutes. All truck drivers were male and all CSWs were female.

Field observations were conducted in locations where truck drivers and/or CSWs spent free time, bought or consumed alcohol and drugs and where truck drivers reportedly looked for sexual partners. The time of the day was varied systematically to cover the morning, afternoon, evening and late night.. Observations were recorded by the field team. (four observers) in a daily diary.

The above information was used to map two main routes related to networks, risk scenes and available health services targeting truck drivers and CSWs.

\section{Data. analysis}

Transcribed in-depth interviews, focus groups and field observations were read to discern participants' views and behaviors regarding the roles of sexual behavior and drug use and HIV/AIDS risk. Descriptive notes were written in the margins to facilitate coding by two of the authors (M. M. and E. K.), these were compared, contrasted and merged to create a single coding scheme with 64 codes. Text with similar codes was examined and compared across interviews, leading to preliminary themes. Codes were generated inductively, using 'open coding' methodology ' (Strauss \& Corbin, 1998). All coded data segments were entered into Atlas.ti and reviewed line-by-line to create sub-codes.

A similar but independent process was used to develop the mapping, whereby two field workers independently developed maps that were compared, contrasted and merged.

Data from in-depth interviews, focus groups, field observations and mapping were triangulated and four main themes related to HIV/ AIDS risk taken were developed.

The study was approved by the Local Ethical Committee in Itajai and the Brazilian Ministry of Health Review Board. Interviewees signed an informed consent form before being interviewed and received the equivalent of US $\$ 5.00$.

\section{Results}

Sociodenwgraphic characteristics

Of thirty long-route truck drivers participating in indepth interviews, 29 were male, one was female and most were aged 30-49 years old. Twenty were married or lived with a stable partner and the majority had up to eight years of education. The majority of truck drivers had a monthly income around US $\$ 600$ and spent 11-17 hours/day on the road (Table I).

Of thirteen CSWs who were interviewed, nine were female and four were male. The majority. were between 19-29 years old, had up to eight years of education and no stable partner. . The majority of CSWs had a monthly income around US \$400 and worked at truck stops, highways or brothels (Table II).

The following main themes were identified: (a) influence of availability and/or inevitability of transactional sex on unsafe behaviors, (b) unsafe sex with different sex partners, (c) frequency of alcohol and drug use and (d) knowledge and attitudes about HIV/STI infection.

Influence of availability and/or inevitability of transactional sex on unsafe behaviors

Truckers described layovers spanning from several hours to several days while their trucks were being loaded, unloaded, refueled or maintained. The long trips and loneliness endured by truck drivers appeared to lead to frequent contact with CSWs:

,... Truckers seem to be a sort of 'soldier in war', you know? I mean, he spends from two weeks to six, eight months alone, out of home ... My Lord! To this poor guy any girl is hot ...' (Male truck driver, 27 years old).

'We stay a long, long time alone, you know? A long time away from our family and there's also our needs, we're men, you know? Anyway, it's quite 
Table 1. Basic sociodemographic characteristics of 30 u'uck drivers interviewed, Itajai, 2003.

\begin{tabular}{|c|c|c|}
\hline Variable & $N$ & $0 / 0$ \\
\hline \multicolumn{3}{|l|}{ Age } \\
\hline 19-29 years & 7 & 23.3 \\
\hline 30-39 years & 5 & 16.7 \\
\hline $40-49$ years & 13 & 43.3 \\
\hline $50-59$ years & 2 & 6.7 \\
\hline+60 years & 1 & $3: 3$ \\
\hline NA & 2 & 6.7 \\
\hline \multicolumn{3}{|l|}{ Gender } \\
\hline Male & 29 & 96.7 \\
\hline Female & 1 & 3.3 \\
\hline \multicolumn{3}{|l|}{ Marital status } \\
\hline Maried/stable union & 20 & 66.7 \\
\hline Single & 10 & 33.3 \\
\hline \multicolumn{3}{|l|}{ Years of formal education } \\
\hline Less than 8 years & 10 & 33.3 \\
\hline 8 years & 10 & 33.3 \\
\hline Less than 1] years & 3 & 10 \\
\hline 11 years & 7 & 23.3 \\
\hline \multicolumn{3}{|l|}{ Monthly income } \\
\hline \$201-\$ 350 & 7 & 23.3 \\
\hline$\$ 351-\$ 700$ & 1 & 43.3 \\
\hline$\$ 701-\$ \quad 1,000$ & 4 & 13.3 \\
\hline$\$ 1,001-\$ 1,4000$ & 3 & 10 \\
\hline$+\$ 1,4000$ & 3 & 10 \\
\hline \multicolumn{3}{|l|}{ Hours driving every day } \\
\hline $\mathrm{Up}$ to $10 \mathrm{hs} /$ day & 9 & 30 \\
\hline 11-17 hs/day & 15 & 50 \\
\hline $18-24$ hs/day & 5 & 16.7 \\
\hline NA & I & 3.3 \\
\hline \multicolumn{3}{|l|}{ Have ever had a road accident? } \\
\hline Yes & 17 & 56.7 \\
\hline No & 13 & 43.3 \\
\hline \multicolumn{3}{|l|}{ How long stay away from home? } \\
\hline Up to 1 week & 18 & 60 \\
\hline $1-2$ weeks & 5 & 16.7 \\
\hline 2-4 weeks & 3 & 10 \\
\hline More than 1 month & 3 & 10 \\
\hline NA & 1 & 3.3 \\
\hline \multicolumn{3}{|l|}{ Alcohol use } \\
\hline Daily basis & 7 & 23.3 \\
\hline Weekly basis & 20 & 66.7 \\
\hline Don't use & 3 & 10 \\
\hline \multicolumn{3}{|l|}{ Drug use } \\
\hline Metamphetamines & II & 36.6 \\
\hline $\begin{array}{l}\text { Metamphetamines \& other stimulants } \\
\text { (crack, snorted cocaine) }\end{array}$ & 2 & 6.7 \\
\hline Injection drug use & - & - \\
\hline Don't use & 17 & 56.7 \\
\hline Total & 30 & 100 \\
\hline
\end{tabular}

easy to find a girl, there's girls all over the highway offering themselves, in the truck stops, they're everywhere. Here in the south it wasn't that much, but nowadays you find gills everywhere. So, it's a bunch of things going on and you just can't resist.', (Male truck driver, 30 years old).
Table II. Basic sociodemographic characteristics of 13 CSWs interviewed, Itajai, 2003.

\begin{tabular}{|c|c|c|}
\hline Variable & $N$ & $\%$ \\
\hline \multicolumn{3}{|l|}{ Age } \\
\hline 19-29 years & 8 & 61.5 \\
\hline 30-39 years & 4 & 30.8 \\
\hline $40-49$ years & I & 7.7 \\
\hline \multicolumn{3}{|l|}{ Gender } \\
\hline Male & 4 & 30.8 \\
\hline Female & 9 & 69.2 \\
\hline \multicolumn{3}{|l|}{ Marital status } \\
\hline Maried/stable union & 1 & 7.7 \\
\hline Single & 12 & 92.3 \\
\hline \multicolumn{3}{|l|}{ Years of formal education } \\
\hline Less than 8years & 6 & 46.2 \\
\hline 8 years & I & 7.7 \\
\hline Less than II years & 3 & 23.1 \\
\hline II years & 3 & 23.1 \\
\hline \multicolumn{3}{|l|}{ lvlonthly income } \\
\hline Up to $\$ 200$ & 5 & 38.5 \\
\hline$\$ 201-\$ 350$ & 2 & 15,4 \\
\hline$\$ 351-\$ 700$ & 5 & 38.5 \\
\hline$\$ 701-\$ 1,000$ & I & 7.7 \\
\hline \multicolumn{3}{|l|}{ How long has been a CSW? } \\
\hline $0-4$ years & 4 & 30.8 \\
\hline $5-9$ years & 4 & 30.8 \\
\hline $10-14$ years & 4 & 30.8 \\
\hline+15 years & 1 & 7.7 \\
\hline \multicolumn{3}{|l|}{ Where s/he works as a CSW? } \\
\hline Truck stops & 4 & 30.8 \\
\hline Brod1els & 5 & 38.5 \\
\hline Highways (only male CSWs) & 4 & 30.8 \\
\hline \multicolumn{3}{|l|}{ Alcohol use } \\
\hline Daily basis & 8 & 61.5 \\
\hline Weekly basis & I & 7.7 \\
\hline Don't use & 4 & 30.9 \\
\hline \multicolumn{3}{|l|}{ Drug use } \\
\hline Marijuana and snorted Cocaine & 4 & 30.8 \\
\hline Injection drug use & - & - \\
\hline Don't use & 9 & 69.2 \\
\hline Total & 13 & 100 \\
\hline
\end{tabular}

On the other hand, some truck drivers felt that CSWs 'harassed' them into availing themselves of their services:

'There's a sort of ... let's say, a sort of 'harassment' you know? Those women (CSWs) go after us and we're human beings, for God's sake! They start just like that: "Hey honey, do you wanna have some fun?" What are you supposed to do? You just can't resist ... ' (Male truck driver, 49 years old).

'Once I met a girl and she hung out with my buddy. Then he left and I stayed here for a while. So she asked me about him twice or three times and then she came on me. But my truck was full and I didn't wanna look for trouble, you know? So 
I took a cab and went to a nightclub downtown. When I came back, around $3 \mathrm{am}$, she was still working in the truck stop. There are thousands of girls like that ... they come after us.' (Male truck driver, 40 years old).

Many truckers had a set of values that emphasized freedom and gave importance to frequent sexual encounters:

'I have my wife, and when I'm at home we have sex around three to four times a week. But when I'm traveling and I hang out: with my buddies, for sure I'll cheat on my wife, I'm not ashamed of that. It's a sort of male thing, you know?' (Male truck driver, 25 years old, 7 years as truck driver).

Depending on the location, sex workers servicing the trucking industry may work alone, in groups or at a brothel:

'I usually work with truck drivers here in the highway, in some truck stops and in bars nearby. But I work all by myself, you know?' (Female CSW, 28 years old).

'It's a sort of brothel, a house with drinks, music and girls. Truck drivers already know what's going on here, so they come already looking for sex,' (Female CSW, 25 years old).

Although relationships between truckers and these women were often 'one-night stands', reports from some truckers and CSWs indicated that some relationships may endure, especially when truckers repeatedly travel a particular route:

'She calls me and we meet in the highway ... Sometimes I also call her to set a date. Then we go to a motel or to her place. Sometimes we even make out in my truck.'. (Male truck driver, 30 years old).

'Sometimes you get interested in some truck driver, then we travel together for a while. They pay our food, we sleep in the truck and sometimes we even get some money back. It seems like we're his girlfriend or wife, you know. I even believed that I was his wife ...' (Female CSW, 34 years old).

\section{Unsafe sex with different sex partners}

Three categories of on-the-road sex partners were identified: CSWs, 'traveling ladies' and employees of truck stops and trucking-related businesses. 'Traveling ladies', as truckers referred to them, rode with truckers on journeys ranging from one day to an entire trip of several weeks or more. Many were young runaways but some were old enough to pose as drivers' wives. They reportedly slept in the cabs and ate with the drivers, often in exchange for sex. Employees of truck stops and trucking-related businesses usually were seen as 'safer' partners, with whom condoms were seldom used, as described in this focus group:

Truck driver 1: 'Sometimes the guy comes into a restaurant and he sees a hot cashier. So he checks her out and starts some sort of conversation .... In the end, you'll never think about it (using condoms).

Moderator: 'But what's the difference?' (between an occasional partner and a CSW).

Truck driver 1: 'Money is the difference.'

Truck driver 2: 'A girl at a restaurant, a fast food (place), she's sort of different, you can trust her ... ' (Focus group with 6 truck drivers).

These sentiments were similar to those reported in in-depth interviews:

'I don't like prostitutes, I don't think it's fine to pay for a women to have sex with me. Bur I had lots of partners around, usually girls who work in restaurants, truck stops and gas stations. This happens mainly when I'm traveling far away and I stay away home for a while.' (Male truck driver, 27 years old).

Most of the truckers interviewed denied ever having sex with a male partner; however, a number of participants: indicated that 'some truckers' use the services of male sex workers, primarily because they were less expensive than female CSWs and were often available:

'I do prefer women, but nowadays you can see some homosexuals in the streets and some are even prettier than the girls. It happened to a friend of mine, we picked up two street girls and he wanted the prettiest one, but mine was a woman and his was a gay man ... ' (J'vlaletruck driver, 25 years old).

Such reports were confirmed in a focus group with six truck drivers:

Truck driver 1: 'There's no doubt about that.. You just can't pretend there's no such thing (as homosexual truck drivers). A long time ago, 
when you say that some trucker was gay, everyone were like "What???" but nowadays ...

Truck driver 2: 'It's quite easy to find it.'

Truck driver 3: 'They're everywhere.'

Truck driver 1: 'It's a sort of demand-supply stuff, you know what I mean?

Truck driver 3: 'Yeah.'

Truck driver 2: 'That's why you can find guys selling sex all over the highway.'

Truck driver 4: 'It's a business, man!'

According to one male sex worker we interviewed, the lack of hotels supporting male CSWs in the sex trade led them to seek out environments where it would be difficult to negotiate condom use:

'Every day I make out with a few truck drivers ... but there's no such thing of motel., You pick up your client, usually a trucker, go to a truck stop, an abandoned place or even to the truck. Nice and easy.' (Male CSW, 30 years old).

\section{Frequency of alcohol and drug use}

Two thirds of truckers used alcohol on a weekly basis; $61 \%$ of CSWs used alcohol daily (Tables I and II). Almost half of truckers used methamphetamines and other stimulants, such as crack-cocaine and snorted cocaine $(43.3 \%)$ but the stimulant most frequently used was methamphetamine. Commercial sex workers reported smoking marijuana and snorting cocaine $(30.8 \%)$. None reported injection drug use (Tables I and II).

The occupational demands of long-haul trucking and the personal ideology of many truckers may be important factors in the social context of their HIVrelated risk behavior.. The majority of truckers drove for over 11 hours per day and over half reported at least one accident (Table II). Many companies required truckers to deliver cargoes more rapidly than they could endure without missing hours of sleep. To make delivery deadlines, truckers frequently drove longer hours than the law permits. Many complained of job related stress:

, ... I used lot of stuff to drive all night long, rebite (a metamphetamine), cocaine, crack, marijuana ... My ex-boss even required us to work by the clock ... He used to give us rebite and make us travel all night long; we had terrible delivery deadlines and we needed the job, who disagreed would be unemployed. And we had family, you know? So we were obligated, there was no way out: I was even involved in a car accident, for such drug using things ..." (Male truck driver, 43 years old).

Substance use, particularly alcohol use, was a common excuse for lack of condom use among truckers:

'When we use drugs or have a couple of drinks we just do not use condoms ... You get dizzy, sort of different, so you don't think about that at all,' (Male truck driver, 23 years old).

'If you have to use it (condom) but if you're drunk, or took lots of drinks, you just forget about: it. It's sort of, you just don't care, or don't remember, whatever.'. (Male truck driver, 27 years old).

Knowledge and auitudes about HIV/STI infection

Most truckers claimed to understand the risk for HIV transmission associated with unprotected sexual intercourse and the importance of condom use to prevent HIV/STIs. However, many fostered myths about HIV transmission. The principal criteria truck drivers reported for selecting a 'safe' sex partner was physical appearance and 'looking healthy'. These beliefs were also endorsed among CSWs. Consequently truck drivers and commercial sex workers who reported frequent unprotected sex with multiple partners often did not consider themselves at risk:

'They say one cannot be infected (with HIV) through toilets seats, spoons/forks and meals. But we always get a little confused ... I mean, truck drivers sometimes use really dirty toilets and we keep thinking if there was no disease on it ... Some guys even say that one can get gonorrhea if your body is hot and you walk barefoot in a cold ground.'. (Male truck driver, 23 years old).

'Always when I have sex with someone without: a condom, I ask if he has something (an STI). I know this is not a $100 \%$ safe but ... 'cause he was cute, hot and it was so good that I just forgot about condom. Sometimes we just forget about it, we think it's OK, you know?' (Female CSW, 24 years old).

Among truck drivers, sexual risks seemed to be mediated by the kind of partnership and kind of sexual activity. For instance, consistent condom use tended to be influenced by intimacy with sexual partner-the more intimacy, the less truck drivers were likely to use condoms. On the other hand, 
truckers seldom used a condom with a steady partner:

'I never ever use it (condom), 'cause I'm always with my wife. But if someday I take one of those girls (CSWs), I gotta use it for sure!' (Male truck driver, 23 years old).

Seldom did truck drivers report using condoms in oral sex; safer sex was considered more important. during vaginaVanal sex:

,... Sometimes I called off one sex date 'cause I had no condoms at all but oral sex with condoms is terrible. I'd rather not to have it.' (Male truck driver, 39 years old).

'I've never used it with oral sex (condom).' . (Male truck driver, 30 years old).

STIs were reported by many truck drivers:

'I already had gonorrhea and a sort of mycosis near my penis.'. (Male truck driyer, 39 years old).

'I had warts, condyloma, then I went to a pharmacy looking for some meds ... It got even worse and I had to look for a hospital.' . (Male truck driver, 25 years old).

'I'm 'macho', you know. what I mean? When I was single, I had lots of partners and lots of venereal diseases. I got almost crazy and once I almost died, I mean it!' (Male truck driver, 59 years old).

Although being engaged in high-risk behaviors, the majority of truck drivers had never sought HIV testing. Only a few participants had looked for a VCT facility, some after engaging in a high-risk behavior but most were compulsorily tested at drug treatment facilities or their companies:

'When I had condyloma I looked for HIV testing and thank God it was negative.' (Male truck driver, 25 years old).

'I was tested for HIV in my company, it's a sort of compulsory exam down there.'. (Male truck driver, age unknown).

'I made it (HIV test) when I looked for a detox clinic. No one can start the treatment there without. getting tested for HIV.: (Male truck driver, 40 years old).

Among those who were never tested for HI V, a low self-perceived risk of HIV infection was the main reason not to seek HIV testing:
'I've never gotten tested (for HIV), 'cause I don't need it.' (Male truck driver, 23 years old).

'I've never looked for that (HI V test). I don't think I have HIV anyway ... ' (Male truck driver, 23 years old).

In contrast with truck drivers, both female and male CSWs had a high self-perceived vulnerability to HIV/STIs and almost all CSWs had already tested for HIV at least once:

'I make it (HIV test) every three months, 'cause I'm a little afraid, you know, we all fear it (HIV infection). Sometimes the condom broke and we get really afraid of getting something, you know?' (Male CSW, 21 years old).

'We make it (getting an HIV test) always, you gotta make it every three months, you know, sometimes you break the condom and you stay for a while in the immunological window, but after three months everything's fine if you keep getting a negative result. . I make it (HIV test) every three months.' . (Female CSW, 21 years old).

\section{Discussion and Conclusion}

High-risk sexual behavior was common among truck drivers in Itajai, who reported frequently engaging in unprotected sexual intercourse with female CSWs and other concurrent_. partners and using alcohol and methamphetamines. The infrequent use of condoms among truck drivers and their low perceived risk was congruent_: with studies in both developed. (Stratford et $\mathrm{al}_{,}, 2000$ ) and developing countries (Gawande et al, 2000; Gysels et al., 2001; Manjunath et al, 2002; Ntozi et al., 2003).

The context of sexual partnerships was an important element that contributed towards unprotected sex among truckers and their sex partners. Truckers reported using condoms more often with CSWs who were 'one-night stands' but less frequently with CSWs or trucking industry employees they had formed relationships with. Interventions geared towards long-haul truck drivers will need to consider their sexual interactions, with other players working along truck driving routes, such as women working in truck stops and restaurants, 'traveling ladies' (who mayor may not be CSWs) and male sex workers.

Although we only interviewed a few male CSWs and many truckers denied personally having sex with male CSWs, these interactions appeared commonplace in Itajai. The lack of safe, priyate locations where sex could occur with male CSWs made it more difficult for either party.' to use condoms. 
There was frequent use of alcohol and drugsespecially methamphetamine -among truck drivers to relieve job-related stress, which in turn led to inconsistent condom use. Structural interventions to change conditions in the workplace are needed, for example to limit the number of consecutive hours truckers are on the road and/or to establish a minimum rest period. Such efforts could directly or indirectly reduce the likelihood that truck drivers engage in substance use or have unprotected sex. This would be important. to evaluate, Our study supports previous studies that suggest that successful interventions among truckers should provide peer education and condom promotion (Laukamm-Josten et al., 2000), improve their knowledge about HIVI AIDS (Lacerda et al., 1997) and foster interdisciplinary approaches (Parker et al., 2000).

Because street-based convenience sampling methods were neither random nor systematic, we cannot generalize our findings to all truck drivers working in the Itajai area. In order to eliminate sampling bias and the danger of repeating studies amongst the same social networks, more rigorous techniques, such as random nomination selection, need to be considered in further studies with this population. Our reliance on self-reported data might lead to some 'socially acceptable' responses, such as consistent condom use, that may have been overreported.

Despite these limitations, the multi-method approach used in this study helped triangulate findings and uncover hotspot areas where interventions could be targeted to truckers, CSWs and other employees in the trucking industry. Prevention efforts need to take into account the conditions and beliefs that affect their behavior (Weeks et al,, 1993; Zimmerman et al, 1995). To reduce the risk of HIV infection among truck drivers and CSWs working along trucking routes, prevention programs need to overcome several impediments, including myths about HIV transmission, low self-perceived risk and denial about the risks associated with unprotected sex and the limited number of venues where HIV/STI education and testing can be confidentially sought. Since we found that truckers and CSWs readily discussed their working conditions, effective interventions could be developed by recruiting truck drivers and/or CSWs to help devise prevention strategies or by using media figures popular with truck drivers to disseminate public health messages. The highly mobile nature of these populations indicates the need for interventions that traverse cities and states and even borders with neighboring countries, taking into account factors such as its seasonal nature and spatial context.

\section{Acknowledgements}

The authors thank the truck drivers, commercial sex workers and others who generously agreed to take time from their busy work schedules to participate in this project.. The study was funded by the Centers for Disease Control and Prevention, UNESCO and the Brazilian Ministry of Health (Grant: \# 207BRA1000). Dr.. Strathdee is supported in part by the endowment. for the Harold Simon Chair Foundation at the University. of California, San Diego, and by a grant: from NIDA (DA19829).

\section{References}

Brazilian Ministry Of Health (2004).. HIV/AIDS and STIs national data. Avaliable at: http://www.aids.gov.br

Gawande, A.Y., Vasudeo, N.D., Zodpey, S.P., \& Khandait, D.W. (2000). Sexually transmitted infections in long distance truck drivers. The Joul'llal fGollullullicable Diseases, 32, 212-215.

Gibney, L.. Saquib, .; \& Metzger, . ]. (2003). Behavioral risk factors for STDIHIV transmission in Bangladesh's trucking industry. Social Science \& Medicine, 56, 1411-1424.

Gysels, M., Pool, R, \& Bwanika, K.. (2001). Truck drivers, middlemen and commercial sex workers: AIDS and the mediation of sex in south west Uganda. AIDS Gal'e, 13, 373-385.

Lacerda, R, Gravato, N.., Mcfarland, IVI., Rutherford, G., Iskrant, K... Stall, R., et al. (1997). Truck drivers in Brazil: Prevalence of HIV' and other sexually transmitted diseases, risk behavior and potential for spread of infection. AIDS, $\quad 11$ (Suppl. ... I), S15 S19.

Laukamm-Josten, U., Mwizarubi, B.K., Outwater, A., Mwaijonga, C.L., Vahdez, I.J., Nyamwaya, D., et al, (2000). Preventing HIV infection through peer education and condom promotion among truck drivers and their sexual partners in Tanzania, 1990-1993. AIDS Gal'e, 12,27-40.

Manjunath, ].V, Thappa, D.M., \& Jaisankar, T].. (2002). Sexually transmitted diseases and sexual lifestyles of long-distance truck drivers: A clinico-epidemiologic study in south India.. InrematiollalJoul'HälofSTD \& AIDS, 13,612-617.

Miles, M.B., \& Huberman, A.M. (1994). Qualitative data analysis (2nd edition). Thousand Oaks: Sage.

MOlTis, M., Podhisita, C., 11(lawer, M.L \& Handcock .. M.S. (1996). Blidge populations in the spread of HIVIAIDS in Thailand. AIDS, 10, 1265-1271.

Muhr, T (1997). ATLASlti , for Ylindows. Berlin: Scientific Software Development.

Needle, RH., Trotter, RTII, Singer, M., Bates, C., Page, ].B. Metzger, D., et al, (2003). Rapid assessment of the HIVIAIDS crisis in racial and ethnic minority. communities: An approach for timely community interventions. A, "eriean J01.1rnal $1 !$ Public Health, 93, 970-979.

Ntozi, J.P., Najjumba, I.M., Ahimbisibwe, F, Ayiga, N., \& Odwee,]. . (2003). Has the HIV/AIDS epidemic changed sexual behaviour of high risk groups in Uganda); A.I; 1 Cllll Health Sciences, 3,107-116.

Parker, RG., Easton, D., \& Klein, C.H. (2000). Structural ban'iers and facilitators in HIV prevention: A review of international research. AIDS, 14 (Suppl,. 1), S22-S32.

Stimson, G.v., Donoghoe, M.C.,. Fitch, C., Rhodes, T,T., Ball, A. \& Weiler, G. (2003). Rapid assessment and response technical guide. World Health Organization (Department of Child and Adolescent Healtb and Development and Department of HIV/ AIDS) Geneva. 
496 M. Malta et al.

Stratford, D., Ellerbrock, T.V., Akins, ].K., \& Hall, H.L.. (2000). Highway cowboys, old hands and Christian truckers: Risk behavior for human immunodeficiency virus infection among long-haul truckers in Florida. Social SaiCilce \& !vledieine, 50, $737-749$.

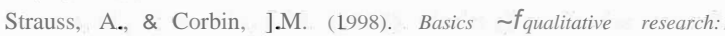
TeeIlltiques "'hit. procedllres for developillg groullded theory (2nd edition). Thousand Oaks: Sage.

Sugihantono, A., Slidell, M., Syaifudin, A., Pratjojo, H., Utami, I.M., Sadjimin, T., et al. (2003). Syphilis and HIV prevalence among commercial sex workers in central Java, Indonesia: Risktaking behavior and altitudes that may potentiate a wider epidemic. AIDS Patielll Care alld STDs, 17,595-600.

Sunmola, A.M. (2005). Sexual practices, barriers to condom use and its consistent use among long distance truck drivers in Nigeria. AIDS Care, 17,208-221. .
Villarinho, L. Bezerra, I., Lacerda, R., Latorre, M.D., Mdo, R., Paiva, V, et al. (2002). Vulnerability to HIV and AIDS of short. route !ruck drivers, Brazil.. (Article in Portuguese). Journal of Public Health, 36, 61-67.

Weeks, M.R.,, Singer, M., \& Schensul,. 1..].. (1993). Anthropology, and culturally targeted. AIDS prevention. Practicing Amhrapol$0, l C y, \quad 15,17-20$.

Zimmerman, M.A., Janz, N.K., \& Wren, P.A., (1995). . I'actors influencing the success of AIDS prevention programs. In $\mathrm{N}$. Freudenber g, \& M. A. Zimmerman (Eds.), AIDS prevemioll : ill the Collullulliry: Lessolls: frolll the first decade (pp. 149-160). Washington: American Public Health Association. 